Kleine Weltgeschichte des demokratischen Zeitalters 
Stefan Bajohr

\section{Kleine Weltgeschichte des demokratischen Zeitalters}

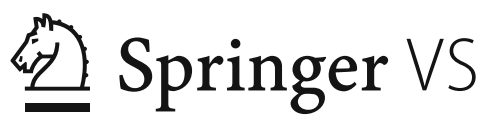


Stefan Bajohr

Heinrich-Heine-Universität Düsseldorf

Deutschland

Die Deutsche Nationalbibliothek verzeichnet diese Publikation in der Deutschen Nationalbibliografie; detaillierte bibliografische Daten sind im Internet über http://dnb.d-nb.de abrufbar.

\section{Springer VS}

(c) Springer Fachmedien Wiesbaden 2014

Das Werk einschließlich aller seiner Teile ist urheberrechtlich geschützt. Jede Verwertung, die nicht ausdrücklich vom Urheberrechtsgesetz zugelassen ist, bedarf der vorherigen Zustimmung des Verlags. Das gilt insbesondere für Vervielfältigungen, Bearbeitungen, Übersetzungen, Mikroverfilmungen und die Einspeicherung und Verarbeitung in elektronischen Systemen.

Die Wiedergabe von Gebrauchsnamen, Handelsnamen, Warenbezeichnungen usw. in diesem Werk berechtigt auch ohne besondere Kennzeichnung nicht zu der Annahme, dass solche Namen im Sinne der Warenzeichen- und Markenschutz-Gesetzgebung als frei zu betrachten wären und daher von jedermann benutzt werden dürften.

Lektorat: Frank Schindler, Stefanie Loyal

Gedruckt auf säurefreiem und chlorfrei gebleichtem Papier

Springer VS ist eine Marke von Springer DE. Springer DE ist Teil der Fachverlagsgruppe Springer Science+Business Media.

www.springer-vs.de 


\section{Inhalt}

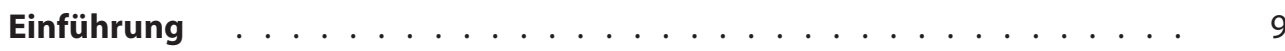

1 Demokratische Ursprünge $\ldots \ldots \ldots$

1.1 Athenische Demokratie und Römische Republik . . . . . . . . . . . 19

1.2 Partizipation im europäischen Feudalismus . . . . . . . . . . . . . . 31

1.3 England: Republik und Glorreiche Revolution ～. . . . . . . . . . . 47

2 Die bürgerlich-liberalen Revolutionen f . . . . . . . . . 63

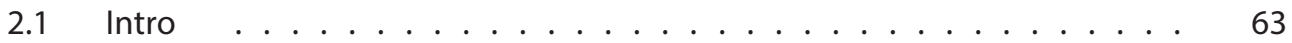

2.2 Amerikanische Revolution (1763-1789) . . . . . . . . . . . . 64

2.2 .1 Intro . . . . . . . . . . . . . . . . . . . 64

2.2.2 Konflikt mit dem Mutterland . . . . . . . . . . . . . 69

2.2 .3 Krieg und Revolution . . . . . . . . . . . . . . . . 73

2.2.4 Die demokratische Verfassung $\ldots \ldots \ldots \ldots$

2.3 Französische Revolution (1789-1799) _ . . . . . . . . . . . 82

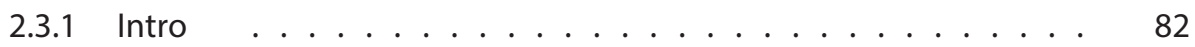

2.3.2 Niedergang des Ancien Régime $\ldots \ldots$. . . . . . . . 83

2.3.3 Revolution . . . . . . . . . . . . . . . . 86

2.3.4 Konstitutionelle Monarchie . . . . . . . . . . . . . . . . . 89

2.3.5 Geburt der Republik . . . . . . . . . . . . . . . . . 93

2.3.6 Nation, Krieg und Bürgerkrieg $\quad \ldots \ldots \ldots$. . . . . . . . . 97

2.3.7 Jakobinische Wohlfahrtsdiktatur . . . . . . . . . . . 102

2.3.8 Abwicklung der Revolution . . . . . . . . . . . . . . . 105

2.4 Europäische Revolutionen (1830-1849) _ . . . . . . . . . . . . 108

2.4 .1 Intro $\ldots \ldots \ldots \ldots \ldots \ldots$

2.4 .2 Vormärz . . . . . . . . . . . . . . . . 113

2.4.3 Die revolutionären Unruhen ～. . . . . . . . . . . . . . 119 
2.4.4 Parlamente und Verfassungen _. . . . . . . . . . . . . . . . 124

2.4 .5 Die Nation . . . . . . . . . . . . . . . . . . . . . . . . . 129

2.4.6 Sieg der Reaktion . . . . . . . . . . . . . . . 134

3 Industriegesellschaften .................. 137

3.1 Intro . . . . . . . . . . . . . . . . . . . . . 137

3.2 Die Industrielle Revolution _. . . . . . . . . . . . . . . . 138

3.3 Die Industriegesellschaften des 19. Jahrhunderts . . . . . . . . . . . . 145

3.4 1920er Jahre: Hyperinflation und Weltwirtschaftskrise . . . . . . . . . 155

3.5 Die Weltwirtschaft nach dem Zweiten Weltkrieg _. . . . . . . . . . . . 160

4 Weltbevölkerung . . . . . . . . . . . . . . . . . . . 175

4.1 Intro . . . . . . . . . . . . . . . . . . . . . . . . . . 175

4.2 Dynamik des Bevölkerungswachstums (1800-2001) . . . . . . . . . . 177

5 Nationen und Demokratie _. . . . . . . . . . . . . . . . 193

5.1 Intro . . . . . . . . . . . . . . . . . . . . 193

5.2 »Nation building « all'italiana: Risorgimento (1820-1870) . . . . . . . . 194

5.3 »Nation building " made in USA: Civil War (1849-1877) . . . . . . . . . 204

5.4 »Nation building ${ }^{2}$ deutscher Art: von oben (1860-1871) . . . . . . . . 213

6 Epoche des Imperialismus f. . . . . . . . . . . . . . . . 221

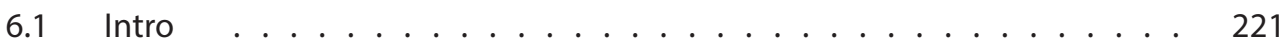

6.2 Am Ende der ersten kolonialen Ausdehnung . . . . . . . . . . . . . . 222

6.3 Zweite koloniale Ausdehnung (1815-1882) . . . . . . . . . . . . 224

6.3.1 Afrika .................... 229

6.3.2 Asien ....................... 235

6.3.3 Australien und Ozeanien _. . . . . . . . . . . . . 239

6.3.4 Amerika ................... . 240

6.4 Hochimperialismus $(1883-1914)$. . . . . . . . . . . . . . 246

$7 \quad$ Erster Weltkrieg _. . . . . . . . . . . . . . . . 253

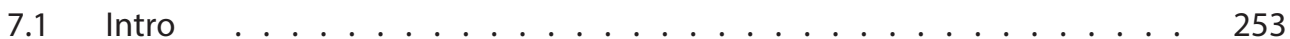

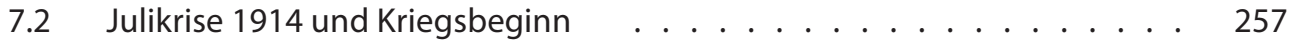

7.3 Kriegswirtschaft ..................... 261

7.4 Die militärischen Auseinandersetzungen (1914-1918) . . . . . . . . . 264

7.4.1 Kriegsverlauf in Europa . . . . . . . . . . . . . . . . 264

7.4 .2 U-Boot-Krieg . . . . . . . . . . . . . . . 267

7.4.3 Außereuropäische Kriegsschauplätze . . . . . . . . . . 268

7.5 Die Novemberrevolution in Deutschland . . . . . . . . . . . . . . . . 270

7.6 Der Frieden . . . . . . . . . . . . . . . . . . . 272 
8 Russische Oktoberrevolution und Stalins Autokratie . . . . . . . . 275

8.1 Intro . . . . . . . . . . . . . . . . 275

8.2 Europäische Arbeiterbewegung bis 1917 . . . . . . . . . . . . . . 277

8.3 Die Oktoberrevolution in Russland (1883-1922) . . . . . . . . . . . . 281

8.4 Neue Ökonomische Politik, Kollektivierung und Industrialisierung . . . . . . . . . . . . . . . . . . . 292

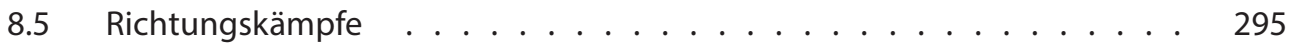

8.6 Schreckensherrschaft $(1927-1953)$. . . . . . . . . . . . . . . . 297

9 Asiatische Großmächte . . . . . . . . . . . . . . . . . . . . . 301

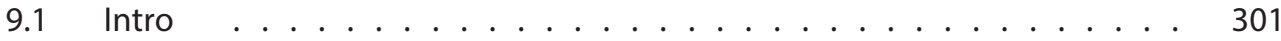

9.2 China - vom ersten Opiumkrieg bis zum Scheitern

9.2.1 Chinas Öffnung . . . . . . . . . . . . . . . . . . . . . . 303

9.2.2 Beute des Imperialismus . . . . . . . . . . . 306

9.2.3 Von den »Boxern«zur demokratischen Republik ...... . 309

9.2.4 Zerfall und Wiederherstellung der Reichseinheit _ . . . . . . . . 314

9.2.5 Vom »Herbsternte«-Aufstand zur Volksrepublik . . . . . . . . . 317

9.2.6 Die ersten 40 Jahre der Volksrepublik . . . . . . . . . . . . . . 322

9.3 Japan - vom Ausklang der Tokugawa-Shōgune

bis zum Frieden von San Francisco (1805-1952) . . . . . . . . . . . . 328

9.3.1 Japans Öffnung . . . . . . . . . . . . . . . . . . . . . . . . . 328

9.3.2 Untergang des Shōgunats . . . . . . . . . . . . 333

9.3.3 Meiji-Restauration ................ . 337

9.3.4 Japanischer Imperialismus . . . . . . . . . . . . . . . 341

9.3.5 Unmittelbare Nachkriegszeit . . . . . . . . . . . . . . 345

9.4 Indien - vom britischen Kaiserreich zur souveränen

9.4.1 »Einheit in der Vielfalt» . . . . . . . . . . . . . . . . . . 348

9.4.2 Britisch-Indien ................. . . 351

9.4.3 Teilung und Unabhängigkeit . . . . . . . . . . . . 357

9.4.4 Kastenwesen und gesellschaftliche Entwicklung . . . . . . . . 359

9.4.5 Politik und Wirtschaft 1947-1991 . . . . . . . . . . . . . . 362

10 Volksmassen gegen die Demokratie:

Faschismus in Europa (1918-1945) . . . . . . . . . . . . . . . . 367

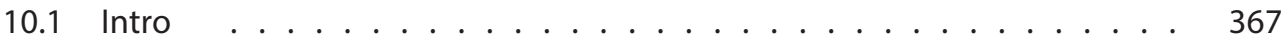

10.2 Faschistische Bewegungen in Italien und Deutschland bis zur Machtübertragung . . . . . . . . . . . . . . 370

10.3 Faschistische Herrschaft . . . . . . . . . . . . . . . . . . . . . . 375

10.3.1 Italien .................... 375

10.3.2 Deutschland .................. 378 
10.4 Faschistische Bewegungen in Europa . . . . . . . . . . . . . . . . . 382

10.5 Widerstand ........................ 384

11 Zweiter Weltkrieg (1939-1945) . . . . . . . . . . . . . . . . 387

11.1 Intro . . . . . . . . . . . . . . . . . . . 387

11.2 Einleitungskriege und -konflikte . . . . . . . . . . . . . 390

11.3 Überfall auf Polen . . . . . . . . . . . . . . . . . . . . 397

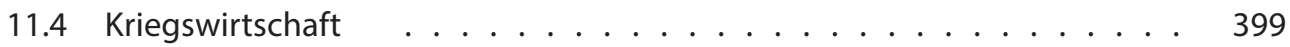

11.5 Ausbreitung des Krieges über Europa und Afrika . . . . . . . . . . . . 402

11.6 Überfall auf die Sowjetunion . . . . . . . . . . . . . . . . . . 405

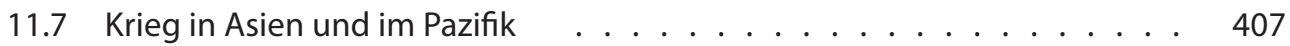

11.8 Niedergang der $»$ Achsenmächte« . . . . . . . . . . . . . . . . 410

12 Der Wettbewerb der Systeme (1945-1989) _ . . . . . . . . . . . . 417

12.1 Intro . . . . . . . . . . . . . . . . . 417

12.2 Auseinanderbrechen der»Anti-Hitler-Koalition« . . . . . . . . . . . 419

12.3 Teilungen: Deutschland, China, Korea, Vietnam ～. . . . . . . . . . . . 422

12.4 Die Bombe . . . . . . . . . . . . . . . . . . . . 430

12.5 Die Diktaturen der USA . . . . . . . . . . . . . . . . . . . . 433

12.6 Widerstand gegen die sowjetische Dominanz . . . . . . . . . . . . 444

12.7 Wendemarken: Kuba, Vietnam, Afghanistan . . . . . . . . . . . 449

12.8 Schauplatz Afrika . . . . . . . . . . . . . . . . . . . . . 453

12.9 Der Nahe Osten . . . . . . . . . . . . . . . . . . . . . . 459

12.10 Entspannungspolitik . . . . . . . . . . . . . . . . . . 469

12.11 Das Ende des Kalten Krieges _... . . . . . . . . . . . . . . . . . 474

13 Völkermord . . . . . . . . . . . . . . . . 483

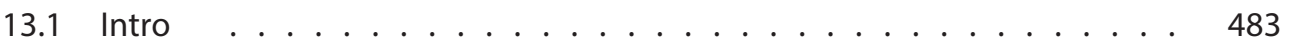

13.2 Demokratie und Völkermord im 19. Jahrhundert . . . . . . . . . . . 488

13.3 Diktatur und Völkermord (1933-1945) . . . . . . . . . . . . . . . . . 497

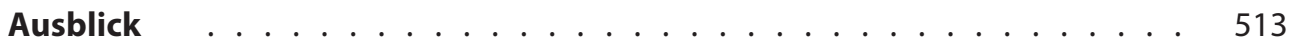

Verzeichnis der Abkürzungen . . . . . . . . . . . . . . . . . . . . . . . 529

Verzeichnis der Abbildungen . . . . . . . . . . . . . . . 533

Verzeichnis der Tabellen . . . . . . . . . . . . . . . . . . 535

Quellen- und Literaturverzeichnis . . . . . . . . . . . . . . . . . . 537

Personenregister .................... . . 561

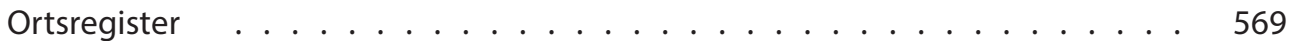

